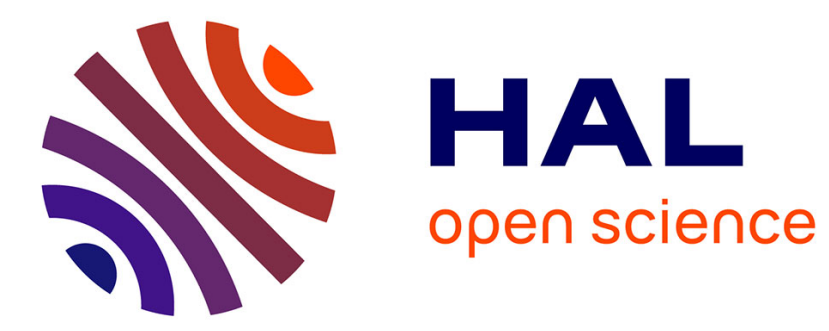

\title{
La autoridad de Tácito en la literatura aforística en torno a 1600: el caso de Antonio Pérez
}

\author{
Paloma Bravo
}

\section{To cite this version:}

Paloma Bravo. La autoridad de Tácito en la literatura aforística en torno a 1600: el caso de Antonio Pérez. Christoph Strosetzki. La Autoridad de la Antigüedad, Serie Autoridad y Poder (4), Universidad de Navarra-Iberoamerinaca-Vervuert, pp.29-48, 2014, La Autoridad de la Antigüedad, 978-84-8489813-9 et 978-3-95487-360-9. halshs-01093603

\section{HAL Id: halshs-01093603 https://shs.hal.science/halshs-01093603}

Submitted on 10 Dec 2014

HAL is a multi-disciplinary open access archive for the deposit and dissemination of scientific research documents, whether they are published or not. The documents may come from teaching and research institutions in France or abroad, or from public or private research centers.
L'archive ouverte pluridisciplinaire HAL, est destinée au dépôt et à la diffusion de documents scientifiques de niveau recherche, publiés ou non, émanant des établissements d'enseignement et de recherche français ou étrangers, des laboratoires publics ou privés. 
Entre los pensadores políticos de la Contrarreforma, ocupa un lugar aparte Cornelio Tácito, a quien leen y citan con «tal entusiasmo y adhesión que ha dado lugar a un movimiento propio: el tacitismo ${ }^{1}$. Son tan abundantes las referencias a Tácito en las páginas de los escritores españoles del siglo XVII ${ }^{2}$ que, según el jesuita francés René Rapin, los términos 'español' y 'tacitista' vinieron a ser sinónimos en Europa. No existe un acuerdo pleno sobre lo que el término 'tacitista' significa ${ }^{3}$. Baste decir, para empezar, que se trata de una corriente política de pensadores que, reivindicando explícitamente el legado de Tácito, pretenden delimitar el Estado como una esfera autónoma que se rige por leyes propias, ajenas a toda referencia ética. Partiendo de Tácito, considerado como el inventor del naturalismo político, estos pensadores plantean la cuestión de la 'razón de Estado', a la vez que intentan echar las bases de una ciencia política. En palabras de José Antonio Maravall:

Hubo [...] escritores que intentaron servirse de Tácito para introducir, encubierto bajo esta capa, el maquiavelismo; y hubo también otros que se dieron cuenta del intento, y combatieron a Tácito con el mismo ardor que a Maquiavelo, considerándolo como padre de las impías sectas de los políticos del tiempo. Pero otros, en cambio, se sirvieron de él como escritor -que poseía por añadidura una serie de buenas condiciones literarias y conservaba el prestigio de la antigüedad latina-, en cuya obra era posible captar la realidad política, tal y como llega a conocerla la razón natural ${ }^{4}$.

A esta última categoría pertenecen autores como Baltasar Álamos de Barrientos, Eugenio de Narbona o Antonio Pérez -quienes, al pretender construir la política como ciencia, se valieron del aforismo como método de adquisición y de transmisión del saber hacer político a la vez que hicieron de Tácito su referencia predilecta ${ }^{5}$.

\section{La penetración de Tácito en España}

A lo largo del siglo XVI y XVII, la influencia de Tácito penetra en España por dos cauces: por un lado, las obras del historiador latino se difunden merced a la circulación manuscrita o impresa de

\footnotetext{
${ }^{1}$ Abellán, 1981, p. 99.

${ }^{2}$ Maravall, 1944, p. 382.

${ }^{3}$ Stegmann, 1969.

${ }^{4}$ Maravall, 1999, p. 76.

${ }^{5}$ Fernández-Santamaría, 1983, pp. 161-203.
} 
algunas traducciones castellanas parciales, y por otro, sus ideas alcanzan gran predicamento gracias a las obras de autores europeos que traducen y comentan los Anales y las Historias.

El interés por Tácito, desde un punto de vista filológico ha sido mediocre en España, donde no ha habido «ningún intento original de fijación del texto» ${ }^{6}$. Durante los siglos XVI y XVII no se hizo ninguna edición crítica de Tácito, siendo la primera, la de C. Sixto y J. Ezquerra que data de $1794^{7}$. Tampoco existe traducción completa acompañada del texto latino que sea anterior a la de esta fecha, si bien, a finales del siglo XVII, Lancina ofreció una primera traducción parcial de Tácito con texto latino (1687). En cambio, sí que existieron versiones castellanas sin el original latino. La primera que se publicó fue la del portugués Sueyro que salió a la luz en Amberes en 1613 bajo el título Las obras de C. Cornelio Tácito, traducidas de latín en castellano ${ }^{8}$; sin embargo, existen versiones anteriores, no estampadas, de otros traductores. De estas traducciones que no fueron llevadas a la imprenta, se conserva la de Antonio de Toledo, que vertió al castellano el primer libro de los Anales y de las Historias en 1590; en cambio, se han perdido otras como la del humanista Simón Abril, la de Ponce de León, la de Lupercio Leonardo de Argensola (en colaboración con Clemente) o la del embajador Benavente y Benavides ${ }^{9}$. Todas ellas son del siglo XVI.

A comienzos del Seiscientos, se imprimieron varias traducciones: a la versión de Sueyro que hemos evocado más arriba, siguió la de Baltasar Álamos de Barrientos en $1614^{10}$ y la de Antonio Herrera y Tordesillas en $1615^{11}$. La de Carlos Coloma data de $1629^{12}$ y la de Lancina ${ }^{13}$ no aparece hasta 1687. Son parciales las de Herrera (que tan solo tradujo los seis primeros libros de los Anales) y de Juan Alfonso de Lancina (que ofreció traducción del primero). Las otras son 'completas' en el sentido que incluyen las principales obras del historiador latino, a saber, los Anales e Historias. Beatriz Antón Martínez llama la atención sobre el hecho de que dichos traductores fueran hombres de toga y de espada y no eruditos:

Es revelador que los traductores de Tácito no fueran profesores de Humanidades ni filólogos de profesión, aun cuando lo fueran de formación y por afición ${ }^{14}$.

\section{Tácito, maestro en política}

De hecho, el aspecto de la obra de Tácito que interesó en España no fue el filológico sino el político. Los traductores castellanos no hicieron comentarios gramaticales para mejorar la lectura de Tácito y su interpretación remitiéndose para el aspecto filológico a los eruditos europeos, Lipsio y Pichena ${ }^{15}$. En cambio, las ediciones españolas van adornadas de consideraciones políticas que toman la forma de comentarios y aforismos tal y como se venía haciendo en Italia, Francia y Flandes.

\footnotetext{
${ }^{6}$ Sanmartí Boncompte, 1951, p. 28.

${ }^{7}$ Sanmartí Boncompte, 1951, p. 28; Antón Martínez, 1991, p. 65.

${ }^{8}$ Sueyro, Las obras de C. Cornelio Tácito, traducidas de latín en castellano por...

${ }^{9}$ Sobre todas estas circunstancias bibliográficas, ver Antón Martínez, 1992, p. 161.

${ }^{10}$ Álamos de Barrientos, Tácito español ilustrado con aforismos.

${ }^{11}$ Herrera y Tordesillas, Los cinco primeros libros de los Anales de Cornelio Tácito, que comienzan desde el fin del imperio de Agusto hasta la muerte de Tiberio. Traducidos en castellano por....

${ }^{12}$ Coloma, Obras de Cornelio Tácito.

${ }^{13}$ Lancina, Comentarios políticos a los Anales de C. Vero Cornelio Tácito.

${ }^{14}$ Antón Martínez, 1991, p. 164.

${ }^{15}$ Cid Vázquez, 2002, p. 33.
} 
Las dos grandes figuras que sentaron las bases de esta literatura en Europa fueron el francés Mureto (1526-1585) y su discípulo flamenco, Justo Lipsio (1547-1606), que fue el humanista que contribuyó en mayor medida a la recepción de Tácito en España. El objetivo de estos traductores y comentaristas era la formación del homo politicus; para ello combinaban conocimientos de la historia, sacados mayoritariamente de Tácito, y elementos neo-estoicos. Con esta mezcla de erudición clásica y de piedad religiosa, elaboraron un arte de gobernar, formando el llamado tacitismo, término con el que se suele designar no solo este tipo de literatura, sino también una corriente política característica de aquella época.

Si bien, la influencia de Tácito se puede rastrear desde principios del siglo $X \mathrm{VI}{ }^{16}$, el tacitismo conoce su máximo esplendor a partir de la década de $1580^{17}$ con la publicación de numerosos comentarios políticos a las obras del historiador latino ${ }^{18}$ : a los de Carlo Pasquale de 1581 (C. Cornelii Taciti....Annalium libri quattuor priores et in hos observationes) siguieron los de Justo Lipsio en 1581 (los Anales) y 1585 (toda la obras). Los de Annibale Scoto datan de 1589 (In P. C. Taciti Annales et Historias Comentarii ad politicam et aulicam praecipue spectantes...), mientras que los de Ammirato (Discorsi sopra Tacito), Botero (Osservazioni sopra Tacito), y Bocalini (Ragguagli di Parnan) están fechados respectivamente en 1594, 1598 y 1613.

El enorme prestigio de Tácito en el Renacimiento está relacionado con el personaje central de los Anales, Tiberio, "mezcla monstruosa de virtudes y de vicios» ${ }^{19}$ y ejemplo de político cauto y austero. De Tácito, fueron también apreciados el pesimismo antropológico, la independencia de espíritu con la que enjuicia las miserias políticas y su estilo inimitable. En España, la referencia al autor latino se convierte en un lugar común de la literatura política, hasta tal punto que Pierre d'Ablancourt en la dedicatoria a su traducción de los Anales (dirigida a Richelieu) escribe:

En este libro se ha engendrado toda la política de España y de Italia; en sus doctos libros se aprende el arte de reinar, en ellos buscan consejo los príncipes de la casa de Austria en los momentos graves ${ }^{20}$.

Desde la influyente aportación de Giovani Toffanin ${ }^{21}$, se considera que se acudió a Tácito en gran medida para elaborar principios no muy distintos de los que podía haber ofrecido el autor del Príncipe. En resumidas cuentas, podemos decir que los ingredientes del tacitismo son, además de la referencia abierta al magisterio de Tácito y a la moral senequista, una alusión implícita pero constante a las problemáticas introducidas por Maquiavelo y el maquiavelismo. Sea más o menos intensa la influencia de Maquiavelo, los escritores formados en Tácito aportan un pensamiento de tipo pragmático, atento al devenir 'real' ${ }^{22}$.

\section{Tacitismo y literatura aforística}

\footnotetext{
${ }^{16}$ Con las primeras ediciones de Tácito realizadas por Beroaldo el joven con colaboración de Alciato (1515 y 1517) o por Rhenano (1519 comentada por Alciato, 1531, 1533...). Sobre la penetración del tacitismo en España anterior a 1580, ver Martínez, 1991, pp. 89-105.

17 Desde los trabajos punteros de Momigliano, 1947 y Fernández-Santamaría, 1986 se sabe que el tacitismo (como lectura política de Tácito) se desarrolló en Europa y en España a partir de 1580; más recientemente Sánchez Lora (2008) ha investigado los círculos tacitistas en torno a Felipe II.

${ }^{18}$ Momigliano, 1947.

${ }^{19}$ Sanmartí Bocompte, 1951, p. 114.

${ }^{20}$ Citado por Marañón, 1977, p. 156.

${ }^{21}$ Toffanin, 1921.

${ }^{22}$ Bermejo Cabrero, 2004, p. LVII.
} 
Ya en 1588, Montaigne escribía hablando de Tácito:

Está tan lleno de máximas que las hay verdaderas y falsas: es un semillero de razones éticas y políticas para provisión y ornamento de aquellos que ocupan un puesto en el gobierno del mundo ${ }^{23}$.

En efecto, la prosa de Tácito está sembrada de sentencias tanto más fáciles de transformar en aforismos cuanto que el autor suele sazonar el relato de los acontecimientos con juicios históricos. No ha de extrañar por lo tanto, que una de las formas predilectas del pensamiento tacitista sea el aforismo. Cabe recordar al respecto, que cuando se reeditaron en Francia en 1600 los comentarios del iniciador de la literatura tacitista, Paschalius, se les dio un nuevo título -Gnomae seu axiomata política ex Tacito- que permitía recalcar el contenido sentencioso del volumen. De hecho, Arnaldo Momigliano ha mostrado que las obras tacitistas se pueden dividir en tres grupos:

1. Una primera categoría de textos proponen una serie de comentarios y aforismos políticos inscritos en las márgenes del texto de Tácito. Estas observaciones constituyen frecuentemente una paráfrasis o un resumen del original que hace hincapié en las principales ideas del fragmento anotado. En este grupo, Momigliano distingue dos maneras complementarias de acercarse al texto: el comentario y el aforismo. Los primeros autores de comentarios son: Carlo Pasquale, el iniciador del género en 1581 y Scoto (1589) mientras que Piccolomini (Advertimenti civil....da sei primi libri degli Annali di Cornelio Tacito, 1609) extrae de la obra de Tácito aforismos marginales.

2. Una segunda serie de autores propone largas disertaciones basándose en una selección de extractos. Ammirato redactó sus 21 libros de discursos políticos publicados en Venecia en 1598 según esta técnica.

3. La tercera manera de nutrirse de Tácito consiste en componer tratados sistemáticos elaborados casi exclusivamente a base de sentencias extraídas de Tácito (por ej., Los Princeps ex C. Tacito de Gölnitz (1636)).

En España, en torno a 1600, la forma más característica del pensamiento tacitista será el aforismo; este aparece como una forma de expresión 'moderna' adaptada a los nuevos contenidos políticos que se están imponiendo.

\section{Modernidad del aforismo tacitista}

4-1 El aforismo político en la literatura sapiencial

El término, de origen griego, con el sentido de 'principio científico expresado de forma concisa', se remonta, como es sabido, a los breves fragmentos de principios y doctrinas recogidos por Hipócrates. Este uso se mantuvo a lo largo de la Edad Media; así en las Etimologías de san Isidoro aparece la voz con su sentido médico: "Aforismo es una frase breve que recoge el sentido completo de un tema propuesto ${ }^{24}$. Los diccionarios de la Edad Media no recogen otro sentido. En cambio, en el Renacimiento, el término desaparece prácticamente aun cuando existe una marcada afición por

\footnotetext{
${ }^{23}$ Montaigne, Ensayos, III, cap. 8 «Del arte de conversar».

${ }^{24}$ "Aforismus est sermo brevis, integrum sensum propositae rei scribens». Se recoge en el apartado 10 del libro IV («De libris medicinalibus»); Isidro, Etimologías, p. 500.
} 
«la sentencia de raigambre clásica y contenido ético tradicional» que se plasma en centenares de recopilaciones tanto en latín como en romance ${ }^{25}$. Erasmo en su introducción a los Adagia define el adagio refiriéndose a otros géneros mínimos (sentencias, apólogos, apotegmas, equívocos...), pero nunca menciona la voz 'aforismo'. Juan Luis Vives en su Escolta del alma, que se puede considerar como libro precursor de los aforismos del siglo $X \mathrm{~V} \|^{26}$, no emplea el término. Los diccionarios españoles y europeos de la época confirman la impresión de que el término ha caído en desuso. En el Dictionarum de Ambrosio Calepino aparecen las voces 'adagio', 'apotegma', 'sentencia' y 'máxima', pero no 'aforismo'. Covarrubias, solo recoge 'aforismo' en su sentido médico clásico, aunque tampoco incluye 'sentencia', ni 'máxima'. En aquellos momentos, 'aforismo' es un término técnico de la medicina que nada tiene que ver con la literatura moral y sentenciosa.

Las cosas cambian a finales del Renacimiento cuando, en un intento por fundamentar el conocimiento, más allá de la retórica y de los argumentos basados en la autoridad de los antiguos, se echa mano del aforismo por considerarlo conectado con un saber hacer empírico. Si hasta entonces los fragmentos sacados de autores reputados apuntan hacia la edificación de los lectores, en la última década del siglo XVI y principios del siglo XVII, aparecen nuevas aspiraciones. La literatura aforística conecta con nuevos métodos de conocimiento que apuestan por el valor del ejemplo por encima del de las autoridades. Francis Bacon, que es uno de los primeros, si no el primero, en plantearse este avance del conocimiento, otorga un papel primordial a la reflexión abierta y libre, frente al carácter estático y estéril del sistema cerrado. La forma idónea para expresar un pensamiento que deja la puerta abierta a la libre interpretación del lector es el aforismo. Así lo expone en el primer libro de El avance del saber, de $1605^{27}$.

\section{4-2 Álamos de Barrientos, Narbona y Pérez, los primeros autores de aforismos en España}

En España el primer autor en utilizar el aforismo en el sentido nuevo que acabamos de recordar es Baltasar Álamos de Barrientos, quien justifica el empleo del término 'aforismo' conectándolo con la idea de que la política es una ciencia.

Un recorrido por las piezas prologales que adornan el Tácito español ilustrado con aforismos -el «Aviso Al lector» (nada relevante para la definición del aforismo), la «Dedicatoria» dirigida a don Francisco Gómez de Sandoval y Rojas y el «Discurso para la inteligencia de los aforismos, uso y provecho de ellos»- permite comprobar que Álamos solo utiliza el término 'aforismo' en el título y al

\footnotetext{
${ }^{25}$ Blanco, 2006b, p. 2. El autor recuerda que la Edad Media contó con una extensa producción de libros sapienciales en los que el aforismo tuvo un papel considerable. Se trataba en realidad de sentencias y máximas procedentes de la Antigüedad y de la Edad Media árabe que la imprenta siguió explotando en sus primeros años. Estas formas breves se empaquetan bajo títulos gráficos, como Bocados de oro, Flores de Filosofía o bajo el epígrafe totalizador 'libro': Libro de los cien capítulos, Libro de los doce sabios, Libro de los buenos proverbios, Libre dels dits de savis e filosofs... Sobre la manera en que surge el aforismo de nuevo cuño en España, son fundamentales los estudios de Blanco, 2006a y $2006 \mathrm{~b}$.
}

${ }^{26}$ Escolta del alma de Juan Luis Vives como un precedente de los libros de aforismos del siglo XVII resulta tentador por varias razones: el número cerrado de elementos (doscientos declarados, aunque en realidad tienen 239), su brevedad, que encierra oscuridad y densidad de sentido, el comentario al aforismo propiamente dicho, el título (Blanco, 2006b, p. 11.)

${ }^{27}$ Blanco, 2006a, pp. 28-34. 
comienzo y final del "Discurso para inteligencia...», empleando en las demás ocasiones las denominaciones tradicionales. Álamos, sin embargo, en dichos textos, postula que la política es una ciencia y que, como tal, se sustenta en una reglas, llamadas 'aforismos':

Y estas proposiciones generales he llamado 'aforismos'; que los derechos llaman reglas: "que es una cosa que brevemente se dibuja, y declara aquello que se pretende enseñar"; sirve para más fácil memoria de ellos; y para más universal aplicación de los casos [...] Quise usar de este nombre de 'aforismos'; aunque pudiera del de reglas, sentencias o conclusiones: por seguir el ejemplo de dos griegos, médico y astrólogo, Hipócrates y Ptolomeo ${ }^{28}$.

Los primeros autores de aforismos en España

Los primeros libros de aforismos publicados en España son, por orden cronológico de elaboración, el de Álamos de Barrientos (1594), el de Antonio Pérez (hacia 1600) y el de Narbona (hacia 1604). Sin embargo, si nos atenemos a las fechas de publicación, el orden cambia, siendo los aforismos de Pérez los primeros (Paris, 1601), los de Narbona (1604) los segundos y los últimos los de Álamos de Barrientos (1614).

Las fuentes empleadas por estos tres autores son muy diferentes. Si bien Álamos de Barrientos ofrece una traducción anotada de Tácito acompañada de aforismos ${ }^{29}$, Eugenio de Narbona, extrae sus aforismos en dos tipos de autores ${ }^{30}$ : los moralistas (como Aristóteles, Cicerón o Séneca) y los historiadores "que analizan la historia» como (Tucídides, Plutarco, Tito Livio, Salustio o los modernos Commines, Guicciardini y Mariana). Con ser las fuentes tan variadas, la cuarta parte de las sentencias remiten a Tácito $^{31}$, de quien dice:

Es el primero de los escritores políticos e historiadores latinos, aunque no en la suavidad del decir, en el decir con más brevedad, advirtiendo las causas de los efectos, escudriñando y descubriendo con malicia lo más secreto de los ánimos, enseñando cuanto a las costumbres y prudencia es necesario, y por esto es de quien más nos hemos valido, no sólo en los ejemplos, pero aún en las doctrinas.

El caso de Antonio Pérez es muy diferente. En efecto, sus máximas están sacadas de sus propias obras (sus Relaciones y Cartas).

Los aforismos de Pérez

Los aforismos del célebre secretario y enemigo de Felipe II, Antonio Pérez, aparecen por primera vez con sus Cartas a diversas personas publicadas sin nombre de impresor ni fecha en París a principios de $1601^{32}$. Bajo este título de Cartas a diversas personas, el antiguo favorito recoge en realidad una serie de opúsculos diversos - básicamente epístolas - entre los cuales destacan los «Aforismos de las cartas españolas y latinas»" ${ }^{33}$. En 1603, Pérez publica con sus Segundas $\operatorname{cartas}^{34}$ una

\footnotetext{
${ }^{28}$ Álamos de Barrientos, Aforismos al Tácito español, pp. 38-39 y pp. LVII-LXX del «Estudio preliminar» de Fernández-Santamaría.

${ }^{29}$ Álamos de Barrientos, Tácito español ilustrado con aforismos.

${ }^{30}$ Narbona, Doctrina política civil escrita por aforismos sacados de la doctrina de los sabios y ejemplos de la experiencia.

${ }^{31}$ Sanmartí Bocompte, 1951, p. 130.

${ }^{32}$ Al respecto ver Pérez Gómez, 1959, p. 80 y pp. 187-193.

${ }^{33}$ Cada uno de los textos que componen esta edición tiene portada propia, pero, como ha demostrado el bibliófilo Antonio Pérez Gómez, debieron de imprimirse y venderse juntos.

${ }^{34}$ Pérez, Segundas cartas.
} 
nueva entrega de aforismos que están sacados tanto de su segunda producción epistolar («Aforismos a las segundas cartas») como de su conocida obra anterior, las Relaciones («Aforismos del libro de las Relaciones»). La primera edición exclusivamente dedicada a los aforismos aparece en París en 1605. Como reza el título -Aforismos de las Relaciones y cartas primeras y segundas de Antonio Pérez y allende de esto algunas cartas a sus amigos y hija ${ }^{35}$ - el volumen recoge todos los aforismos aparecidos hasta la fecha, mezclándolos con alguna que otra pieza breve de carácter epistolar. Nos referiremos a esta edición de 1605 por presentar un triple interés: se trata de la primera versión completa de los aforismos así como del primer libro exclusivamente dedicado a ellos; por otra parte, es una edición bilingüe ${ }^{36}$ que ofrece en las páginas pares la versión castellana y en las impares una traducción francesa; finalmente, es la última obra de Antonio Pérez publicada en vida del autor. Cabe destacar además que éste fue el texto que sirvió de referencia para la primera publicación de los aforismos en España realizada en Madrid en $1787^{37}$.

¿Qué conclusiones se pueden sacar de tales circunstancias bibliográficas?

$1^{\circ}$ Los aforismos son publicados con cartas y opúsculos varios en conjuntos más o menos extensos donde predominan las formas breves y la fragmentación ${ }^{38}$.

$2^{\circ} \mathrm{A}$ la par de las cartas, a las que el autor en más de una ocasión aplica el calificativo de familiares, los aforismos entremezclan asuntos privados con reflexiones políticas.

$3^{\circ}$ Los aforismos fueron los únicos escritos de Antonio Pérez que se vertieron al francés y lo fueron inmediatamente: los primeros aforismos salen de la imprenta a principios de 1601 y son traducidos en 1602, los segundos se publican en castellano en 1603 y circulan en versión francesa a partir de 1605.

$4^{\circ}$ Los aforismos, que fueron publicados después de las Relaciones, corresponden a una segunda etapa de la vida literaria de su autor. Con ellos Antonio Pérez pretende a la vez satisfacer la curiosidad de un público más amplio y reducir a sentencias, fáciles de memorizar, su experiencia

\footnotetext{
${ }^{35}$ El libro fue editado en París por Jean le Bouc, 1605. Hemos manejado el ejemplar de la Biblioteca Nacional de París: R. 18207 y Z. 32367.

${ }^{36}$ Los aforismos de las primeras cartas ya se habían traducido al francés: Aforismes ou Sentences dorées, Paris, Pierre Chevalier, 1602. Solo existen dos ejemplares; uno en la Biblioteca Nacional de Madrid —signatura R. 46086 - y otro en la Mazarina de París - signatura 33727. La traducción es obra del jesuita Jacques Gaultier. Sobre el particular, ver Pérez Gómez, 1959, pp. 208-209.

${ }^{37}$ Para todas las cuestiones bibliográficas, es fundamental el libro de Pérez Gómez, 1959. En particular las pp. 85-86 y p. 92.

${ }^{38}$ Las diferentes piezas que constituyen los volúmenes de las Cartas a diversas personas o las Segundas cartas tienen portadas independientes y si bien en la mayoría de los casos aparecen encuadernadas juntas, a veces aparecen sueltas como una unidad autónoma.
} 
política. En efecto, según afirma en sus aforismos, persigue dos objetivos: por un lado, pretende alcanzar al público español, que no había podido leer las Relaciones, prohibidas por la censura:

Si hubiere contentado este trabajo, les ofrezco otro de sacarles los Aforismos del libro de las Relaciones de Antonio Pérez mientras él saca a la luz los demás escritos. Porque no dejen los medrosos, y vasallos del respecto de gozar de lo poco bueno que tuviere aquel libro por el miedo con que le leen. Dígolo porque un personaje le dijo al autor: «Señor Antonio, de una corte sé que leerían con mucho gusto el libro de vuestras Relaciones, si no estuviesen mezcladas con vuestros agravios y dolores [...]» ${ }^{39}$.

Por otro lado y situándose en la órbita del tacitismo, Pérez, a imitación de Justo Lipsio y de Bitonto ${ }^{40}$, quienes extrajeron aforismos de las obras de Cornelio Tácito, quiere sacar de sus propias cartas y relaciones una serie de máximas políticas. Proyecto ambicioso tanto desde un punto de vista literario como político, en el que Antonio Pérez desempeñará paradójicamente a la vez el papel de autoridad citada y el de recopilador de sentencias.

Como ya lo habían hecho otros autores antes, Pérez sitúa sus reflexiones en la esfera de los aforismos de Hipócrates, presentando sus máximas como remedio para los males que aquejan a los políticos $^{41}$. El supuesto colector de los aforismos es el propio Antonio Pérez. Andrea Herrán y Modesto Santos López, en el estudio introductorio de su libro Sentencias político-filosófico-teológicas (en el legado de Antonio Pérez, Francisco de Quevedo y otros). Del tacitismo al neoestoicismo ${ }^{42}$, han dedicado varias páginas a demostrar que el colector de aforismos y el comentarista de estos son la misma persona (Antonio Pérez). Con ello pretenden rebatir el punto de vista de Astrana Martín, quien pensaba que los aforismos morales sacados de las cartas de Antonio Pérez era « trabajo de mano ajena $»^{43}$. Coincidimos con el análisis de A. Herrán y M. Santos, si bien es necesario puntualizar que Antonio Pérez no pretende en ningún momento mistificar realmente a sus lectores sino jugar con las convenciones literarias del género que implicaban que el autor del texto de que se sacaban

\footnotetext{
${ }^{39}$ Sobre el peso de la censura en la obra de Pérez ver Bravo, 2013a y Bravo, 1998.

${ }^{40}$ Coincidimos con Gustav Ungerer, 1976, quien considera que la alusión a Bitonto es probablemente una manera encubierta de referirse a Álamos de Barrientos.

El texto completo, sacado de la carta prefacio de los Aforismos a las cartas españolas y latinas... fol. 2, es: «Yo con la obligación que cada uno tiene a su profesión y arte, o sea a su inclinación natural, he querido a la curiosidad, por ser uno de los suyos, el trabajo que he tomado en sacar los Aforismos de las cartas españolas y latinas de Antonio Pérez. Llamo los así a imitación de Bitonto que exprimió y destiló a Cornelio Tácito por entretenimiento y curiosidad suya entre sus mayores y diferentes estudios. Papel, que él intituló, Aforismos de Cornelio Tácito. Hube le a las manos de un curioso: que yo estimo en mucho por ser tal persona sobre tal autor. Y aunque sea tan diferente este autor de aquel destilador del otro, agradézcame la curiosidad mi ocupación para hacerle este presente: Si quiera porque fuera de algún valor lo destilado, puedan entrar a pasear por el libro, como por un prado, donde hay tales yerbas, y flores: Y si no fuere de ninguna estima excusarse de buscar, y leer el libro. Adiós».

${ }^{41}$ El subtítulo de la edición francesa no deja ninguna duda sobre la dimensión política de los aforismos: Dans lesquelles on peut remarquer une très belle instruction pour les Rois, Princes et Sujets, pour les Supérieurs et inférieurs: chose très utile et nécessaire pour la conservation et augmentation des Royaumes, Républiques et de toutes Communautés.

${ }^{42}$ Herrán y Santos, 1999.
} 
las sentencias y el curioso que las colectaba no fuesen la misma persona para no incurrir en pecado de inmodestia.

En el prólogo escrito por el colector de los segundos aforismos, estos son comparados con hermosas hierbas y flores que «destiladas, y exprimidas dan lo bueno que tienen para el uso y beneficio humano». Según esto, el lenguaje se puede comparar con «las hierbas y flores y los conceptos a la virtud de ellas». Las sentencias políticas de Antonio Pérez obedecen, pues, a dos metas complementarias y tradicionales en el género sentencioso: agradar con su belleza (como las flores que seducen la vista y el olfato) y sanar con los principios benéficos encerrados en ellas. La virtud curativa de las plantas se obtiene extrayendo, exprimiendo y destilando el jugo de las flores, de ahí que el colector de aforismos se refiera a sí mismo con el nombre de 'destilador'. Por lo demás, la metáfora de la destilación evoca la brevedad y densidad características del género. Los aforismos de Antonio Pérez, fieles a este precepto, llaman la atención por su concisión que a menudo raya en oscuridad $^{44}$. Continuando con la metáfora, por lo demás totalmente tópica del aforismo/flor, la lectura del libro queda comparada con un «pasearse [...] como por un prado». Se trata pues de una lectura abierta en la que el lector puede ir de flor en flor sin que su camino esté trazado de antemano. Esto implica que cada sentencia sea una unidad autónoma de sentido y que puedan ser entendidas con independencia del orden en que se lean. Los aforismos constituyen un discurso discontinuo que conlleva no solo una lectura libre, sino también activa. En efecto, el lector ha de restablecer los nexos lógicos implícitos. Como lo subrayará el propio Gracián en El Discreto ${ }^{45}$, para comprender la prosa de Antonio Pérez, es necesaria una lectura «a todo entender» que transforma al lector en descifrador de enigmas.

La presencia de Tácito y la impronta del tacitismo

Si nos atenemos a criterios cuantitativos, la impronta concreta del escritor latino en la prosa pereciana es mínima: Francisco Sanmartí Boncompte ${ }^{46}$ ha señalado tres fragmentos en los que la imitación o la referencia a Tácito es inequívoca:

\footnotetext{
${ }^{43}$ Astrana, 1932, pp. XXXI-XXXVI.

${ }^{44}$ Él mismo, en una de sus epístolas latinas, define su estilo como obscurum \& melancholicum (citado por Ungerer, 1975, p. 325).

45 En El Discreto, Gracián, a la hora de dar un ejemplo de lo que es un 'buen entendedor', echa mano del ejemplo de Antonio Pérez:

Doctor: Las verdades que más nos importan vienen siempre a medio decir.

Autor: Así es, pero recíbanse del advertido a todo entender.

Doctor: Eso le valió a aquel nuestro Anfión aragonés, cuando perseguido de los propios, halló amparo y aun aplauso en los coronados Delfines extraños.

Autor: Tan poderosa es una armonía, y más de tan suaves consonancias, como fueron las de aquel prodigioso ingenio.

${ }^{46}$ Sanmartí Boncompte, 1951, pp. 169-171.
} 
1. Un pasaje de las Relaciones imitado de las Historias, I, 36, cuando evoca los halagos de que le hacía objeto el pueblo de Zaragoza durante su encarcelamiento en dicha ciudad :

Pedían le los mismos que se mostrase contento porque se aquietase el pueblo, que se dejase tocar y ver de las gentes. Tocar digo porque le iban tocando las manos y apretándoselas y besándoselas los que podían, en señas de parabién común.

2. Y dos alusiones a los Anales:

- La primera cuando, como instrumento de Felipe II para matar a Escobedo, se identifica con Pisón, que eliminó a Germánico por orden de Tiberio.

- La segunda cuando atribuye la intención del conde de Barajas de envenenarle «a que habían leído a Cornelio Tácito en otros casi semejantes ejemplos». Una nota marginal indica: «el de Plancina, mujer de Pisón».

Más allá de estas referencias concretas, Sanmartí Boncompte señala, en tono peyorativo, como la prosa de Antonio Pérez se ve impregnada del modelo latino:

Imita ante todo el estilo de las Historias, pero con gran desventaja, distrayendo la atención del lector con continuas consideraciones políticas, hiperbólicas enumeraciones y prolongados lamentos.

De hecho el autor de las Relaciones reivindica claramente a Tácito como modelo literario:

¿Qué hiciera Cornelio Tácito si topara con los papeles de Antonio Pérez? Cuyo intento a mi juicio fue escribir naturales de Príncipes y sus afectos e inclinaciones porque no se creyesen los hombres que eran otra cosa que hombres. De gran provecho para el género humano.

Comentando este fragmento, escribe Sanmartí Boncompte que Antonio Pérez «tuvo la pretensión de ser su propio Tácito». Nos gustaría hacer hincapié en esta idea completándola y quitándole toda carga negativa.

En efecto, Antonio Pérez se valió no solo del modelo de Tácito para escribir sus Relaciones, en las que se transformaba en el historiador de sus propias desventuras políticas ${ }^{47}$, sino que imitó también a los autores tacitistas cuando extrajo de sus propios escritos una serie de aforismos.

Cabe subrayar la originalidad de Antonio Pérez con respecto a los demás recopiladores de aforismos: en efecto, es a la vez el protagonista de los hechos narrados en las Relaciones, el autor del texto que refleja su recorrido político y el colector de aforismos que va entresacando de este relato una serie de máximas políticas. Asume estas tres identidades mediante un desdoblamiento literario: en las Relaciones, habla de sí mismo en tercera persona de tal manera que quedan separadas la identidad del historiador y la del protagonista de los hechos narrados; en los Aforismos o sentencias sacadas de las Cartas españolas y latinas -y aun cuando él es a la vez el autor del texto del que se extraen los escolios y el colector de los aforismos que de él se sacan-, mantiene la ficción de que se trata de dos personas diferentes. Sirva de ejemplo de este desdoblamiento de Antonio Pérez en "autor» y en colector de aforismos, el siguiente extracto de El curioso a todos, que es un breve prefacio al libro en el que se anuncian 700 sentencias:

\footnotetext{
${ }^{47}$ «...pero yo no aseguro que falte algún Cornelio Tácito a este siglo como a otro» (en boca de un cortesano escandalizado por la suerte del secretario).
} 
Si el número [de los aforismos] es mayor a la substancia de ellos, no es mía la culpa sino del autor de los escritos que no les dio más jugo que poder sacar; pero las gracias no las debo perder yo por esto, antes se me deben mayores por haber gastado mi tiempo en servirles si les pareciera mal gastado.

El desdoblamiento cobra importancia conforme Pérez va sacando nuevas entregas de máximas: si en los Aforismos de las primeras cartas, apenas es posible delinear la personalidad del compilador de aforismos, que solo se manifiesta a través del tipo de sentencias recogidas, este compilador irá adquiriendo progresivamente un perfil sicológico propio, hasta convertirse en el rival literario del autor de las Relaciones y Cartas. El juego de emulación y de competición entre el autor y el colector se expresa en los comentarios que ilustran los Aforismos de las segundas cartas:

Si no dijera [el autor] lo último, yo lo añadiera por vuelo de mi pluma; y bien lo pudiera el autor dejar en el tintero para que otro ganara gracias con ello ${ }^{48}$.

La supuesta rivalidad entre Pérez/autor y Pérez/colector de aforismos se plasma en desdoblamientos lúdicos como cuando en el comentario al aforismo 55 de las Segundas cartas, el 'aforista' insiste en que ambos comparten un mutuo recelo frente a los poderosos: «Aforismo parece pero declárelo quien conoce de reyes; que yo [el colector de máximas] no querría conocerlos, ni el autor [Antonio Pérez] haberlos conocido». En «El Curioso a todos», el hacedor de aforismos es comparado con los cortesanos «que se visten de las colores de las persona a quien siguen». En varios comentarios, el colector presenta su trabajo como una laboriosa imitación de la obra del autor, ironizando sobre el carácter servil de su tarea que consiste en transcribir los pasajes notables, como lo haría un niño que aprende a escribir ${ }^{49}$. Esta imitación, acababa desembocando en un proceso de identificación del aprendiz con el autor anotado: «...me voy haciendo persona de Estado» nos dice el 'aforista' en el comento a la sentencia 75 de las Relaciones. Es decir que, así como los tacitistas pretendían convertir a sus lectores en 'políticos' capaces de extraer de Tácito enseñanzas para el tiempo presente, así el lector que va libando en las obras de Antonio Pérez ha de ser capaz de fraguar, por emulación imitativa, su propia pericia política ${ }^{50}$.

En otro lugar no vacila en presentarse como un trapero que trabaja con material de desecho: «En general hablo como ropavejero que hace vestidos de provisión sin tomar medida a nadie y el que llega sin pensar se le halla hecho a su medida ${ }^{51}$. Resulta curiosa esta reivindicación de una especie de 'Prêt-à-porter' (que no 'prêt à penser') del pensamiento político. Dicha trivialización jocosa

\footnotetext{
${ }^{48}$ Ver el Comentario al aforismos 161 de las Segundas cartas.

49 «El traducir libros es como copiar y escribir el niño por materia. También tendrá el autor por tal este mi trabajo que casi es lo mismo. Por eso me desmando algunas veces» (Aforismo 129, Segundas cartas).

${ }^{50}$ En esta dialéctica, Antonio Pérez asume conjuntamente tres papeles: el del ejemplo histórico presentado para escarmiento del lector, el del autor de los anales que desentrañan los secretos del reinado de Felipe II y el del curioso que extrae aforismos de dicha materia. Dicha actividad de 'aforista' le convierte además -y este será su cuarto papel- en un lector y en un político modélicos, pues extrae de la historia enseñanzas adaptadas a sus propias circunstancias.

51 «Aforismos de las Segundas cartas», 127.
} 
recuerda que para Antonio Pérez la materia política no ha de situarse en la esfera de las sesudas especulaciones y que ha de ser asequible para todos. De hecho, en la «Carta a un amigo Consejero de Estado ${ }^{52}$, Antonio Pérez ridiculizaba a quienes

Nos quieren vender por ciencia infusa ésta; que Estado es alguna quimera, alguna metafísica incomprensible, alguna esencia de aquéllas tan subidas, que se van todas en humo meneándolas. Porque tales me parecen, señor, los consejos y ciencias de los tales, y semejantes a estos empíricos y alquimistas que pretenden a darnos a entender que sus destilaciones son medicinas sacadas de la botica de Esculapio ${ }^{53}$.

Conclusión

Si a la hora de concluir nos volvemos a plantear la cuestión de la autoridad de Tácito y de su significación en la obra de los tres primeros autores de aforismos políticos en España, podemos decir: que Pérez, Narbona y Álamos de Barrientos escriben en un momento en que el humanismo ha entrado en su fase tardía y se aparta de todo método que pretenda argumentar a partir de bases autoritarias; en este contexto, la práctica de los escolios a la obra de Tácito permitirá emanciparse de la tradición aristotélico-tomista. Como la política consiste en gran medida en tener conocimiento de la psicología humana (bien sea a través de la experiencia propia o de la experiencia contenida en los libros de historia) para extraer de él las conclusiones oportunas, Tácito representa para estos autores una fuente inagotable de enseñanzas, pero también un modelo. Se pueden escribir otras Historias y otros Anales a imitación de los del gran historiador latino y se pueden extraer de estas nuevas historias, nuevo acopio de máximas. Desde este punto de vista es significativo lo que Antonio Pérez escribe a propósito de su propia obra: "La ciencia de los príncipes es como la astrología; que pueden saber más los modernos que los pasados, por las más pruebas y experiencias» ${ }^{54}$.

Amparados casi exclusivamente en Tácito, a quien, sin embargo, apenas citan, los Aforismos de Antonio Pérez son los primeros en liberarse totalmente de la tutela de las autoridades clásicas. Al sacar sus máximas de su propia producción anterior, el antiguo secretario de Estado abre la vía a quienes, como La Bruyère o Gracián, escribirán libros de sentencias creadas ex profeso sin necesidad de recurrir a ninguna autoridad que avale su contenido doctrinal ${ }^{55}$. En la obra de Antonio Pérez, Tácito es a la vez pretexto y autoridad suprema, ya que lo que pretende, al inscribirse en la estela del historiador latino, es liberarse definitivamente de la autoridad de los antiguos para ofrecerse como ejemplo de una moderna manera de gobernar.

\section{Bibliografía}

\footnotetext{
${ }^{52}$ Pérez, Segundas cartas, carta LXVI.

53 En la carta "A un amigo consejero de Estado» (Segundas cartas LXVI) escribe: "Cuán fácil y común sea la ciencia que llaman de Estado»; en las Relaciones: « [...] le pondré a la vista el camino que ha de seguir un rey prudente y un buen consejero de Estado; y le haré esta ciencia más llana, más común que la de un pastor». Sobre la aproximación empirista de Pérez a la política ver Fernández Santamaría, 1986, pp. 249-250.

54 "La pluma de Antonio Pérez a los curiosos de la lengua española», Pérez, Aforismos de las Relaciones y Cartas primeras y segundas de Antonio Pérez y allende de esto algunas cartas a sus amigos y hija.

${ }^{55}$ Sobre esta cuestión, ver Bravo, 2013b.
} 
Abellán, J. L., Historia crítica del pensamiento español, III («Del barroco a la ilustración»), Madrid, Espasa-Calpe, 1981.

Álamos de Barrientos, B., Aforismos al Tácito español, ed. J. A. Fernández-Santamaría, Madrid, Centro de Estudios Constitucionales, 2 vols., 1987.

- Tácito español ilustrado con aforismos, Madrid, Luis Sánchez, 1614.

Antón Martínez, B., El Tacitismo en el siglo XVII en España. El proceso de 'receptio', Valladolid, Universidad de Valladolid, Serie Lingüística y Filología núm. 11, 1991.

Aranda Pérez, F. J., «Recetarios políticos. Aforismos tacitistas en la 'Escuela de Toledo' en el primer tercio del siglo XVII», Conceptos: revista de Investigación graciana, 4, 2007 , pp. 13-32.

Astrana Martín, L., «Introducción», F. de Quevedo, Obras en prosa, Madrid, Aguilar, 1932.

Bermejo Cabrero, J. L., «Estudio preliminar», en Comentarios políticos a Tácito, ed. J. A. de Lancina., Madrid, Centro de Estudios Constitucionales, "Clásicos del Pensamiento Político y Constitucional Español», 2004, pp. XI-LXVII.

Blanco, E., «Introducción», en Centellas de varios conceptos, ed. J. Senantí, Barcelona, José de Olañeta editor, 2006a, pp. 13-72.

- Aforismos políticos contra sentencias morales: el caso del siglo XVII, Universidad Carlos III de Madrid. Instituto de Estudios Clásicos sobre la Sociedad y la Política «Lucio Anneo Séneca», 2006b (http://hdl.handle.net/10016/493)

Bravo, P., "Las Relaciones de Antonio Pérez, un texto en movimiento", en Felipe II (1527-1598) Europa y la monarquía católica, ed. J. Martínez Millán, Madrid, Editorial Parteluz, 1998, t. IV, pp. 1124.

- «Censure, autocensure et rhétorique du secret dans les Relaciones d’Antonio Pérez: du silence imposé vers sa mise en scène», en Les voies du silence, ed. A. Merle y A. Guillaume, Paris, Presses de l'Université de Paris-Sorbonne, 2013a, pp. 215-231.

- "La rhétorique de l'ajout chez un écrivain politique espagnol : le cas d’Antonio Pérez, secrétaire d'Etat de Philippe II», en Le post-scriptum et la rhétorique de l'ajout, ed. S. Crinquand et C. SeréeChaussinand, Lyon, Merry World, coll. «Anglophilia», 2013b.

Cid Vázquez, M.T., Tacitismo y razón de Estado en los comentarios políticos de Juan Alfonso de Lancina, Madrid, Fundación universitaria española, 2002.

Coloma, C. , Obras de Cornelio Tácito, Douai, En Casa de Marcos Wion, 1629.

Fernández-Santamaría, J. A., Razón de estado y política en el pensamiento español del Barroco (15951640), Madrid, Centro de Estudios constitucionales, 1983.

- «Estudio Preliminar», en Aforismos al Tácito español, ed. B. Álamos de Barrientos, Madrid, Centro de Estudios Constitucionales, 1987, pp. X-CXLVII.

Herrán, A. y Santos López, M., Sentencias político-filosófico-teológicas (en el legado de Antonio Pérez, Francisco de Quevedo y otros). Del tacitismo al neoestoicismo, Barcelona, Anthropos, 1999. 
Herrera y Tordesillas, A., Los cinco primeros libros de los Anales de Cornelio Tácito, que comienzan desde el fin del imperio de Agusto hasta la muerte de Tiberio. Traducidos en castellano por..., Madrid, Juan de la Cuesta, 1615.

Isidro, Etimologías, traducción de J Oroz Reta y M. A. Marcos Casquero, Madrid, Biblioteca de Autores cristianos, 1982-83, vol. I.

Lancina, J. A., Comentarios políticos a los Anales de C. Vero Cornelio Tácito, Madrid, En la Oficina de Melchor Álvarez, 1687.

Marañón, G., Antonio Pérez, Madrid, Espasa-Calpe, 1977 [1947].

Maravall, J. A, Teoría española del estado en el siglo XVII, Madrid, 1944.

- Estudios de Historia del pensamiento español. El siglo del barroco, Madrid, Centro de Estudios Constitucionales, 1999. [reedición de Cuadernos Hispanoamericanos, octubre-diciembre, 1969, núms. 238-340].

Momigliano, A. D., "The First Political Commentary on Tatitius», The Journal of Roman Studies, XXXVII, 1947, pp. 91-101.

Montaigne, M. de, Ensayos, trad. de Picazo y Montojo, Madrid, Cátedra, 1985-1987.

Narbona, E., Doctrina política civil escrita por aforismos sacados de la doctrina de los sabios y exemplos de la experiencia, Madrid, Viuda de Cosme Delgado, 1621.

Pérez Gómez, A., Antonio Pérez escritor y hombre de estado, Cieza, "...la fonte que mana y corre...», 1959.

Pérez, A., Aforismos de las Relaciones y Cartas primeras y segundas de Antonio Pérez y allende de esto algunas cartas a sus amigos y hija. Les Aphorismes des Relations et premières et secondes lettres à ses amis et à sa fille, Paris, J. Le Bour, 1605.

- Aphorismes ou sentences dorées extraites des lettres tant espagnoles que latines d'Antoine Peres, Paris, Pierre Chevalier, 1602.

- Cartas de Antonio Pérez secretario de Estado que fue del rey católico, don Felipe II de este nombre para diversas personas después de su salida de España, París, s.i., s. d.

- Las obras y relaciones de Antonio Pérez, Genève, Jean de la Planche, 1631.

- Les lettres d'Antonio Perez...écrites à diverses personnes depuis sa sortie d'Espagne Paris, Toussaint Quinet, 1[6]39.

- Les ceuvres morales, politiques et amoureuses d'Anthonio Pérez, Paris, Toussaint Quinet, 1642.

- Relaciones de Antonio Pérez según la copia imprimida en París 1624, París, 1624.

- Relaciones de Antonio Pérez, secretario de Estado que fue del rey de España, Don Felipe II de este nombre, París, s. i, 1598.

- Relaciones y cartas [1598], ed. A. Alvar Ezquerra, Madrid, Turner, 1986.

- Retrato al vivo del natural de su fortuna de Antonio Pérez, Rhodanusia [Lyon], A. Traversario, 1625.

- Segundas cartas de Antonio Pérez (Fama meliore quam Fortuna). Más los aforismos de ellas sacados por el curioso que sacó las primeras. Del mismo los aforismos del libro de las Relaciones, París, Francis Hubi, 1603.

- Segundas cartas, París, Francis Huby, 1603. 
Sánchez Lora, J. L., Arias Montano y el pensamiento político en la corte de Felipe II, Huelva, Biblioteca Montaniana, 2008.

Sanmartí Boncompte, F., Tácito en España, Barcelona, Consejo Superior de investigaciones científicas, Instituto «Antonio Nebrija», Publicaciones Emérita, 1951.

Stegmann, A., "Le tacitisme: programme pour un nouvel essai de définition", II pensiero político, anno II, 3, Florencia, 1969, pp. 445-558.

Sueyro, E. Las obras de C. Cornelio Tácito, traducidas de latín en castellano por, Amberes, en Casa de los Herederos de Pedro Bollero, 1613.

Toffanin, G. Machiavelli e il Tacitismo, Padova, 1921.

Ungerer, G., A Spaniard in Elizabethan England: The correspondence of Antonio Pérez's exile, London, Tamesis Books, 2 vols., 1975. 